\title{
Mediastinal paragangliomas: association with mutations in the succinate dehydrogenase genes and aggressive behavior
}

\author{
Hans K Ghayee*, Bas Havekes ${ }^{1,2 *}$, Eleonora PM Corssmit ${ }^{2}$, Graeme Eisenhofer ${ }^{3}$, \\ Stephen $R$ Hammes, Zahid Ahmad, Alexander Tessnow, Ivica Lazúrová , \\ Karen T Adams ${ }^{1}$, Antonio T Fojo ${ }^{5}$, Karel Pacak ${ }^{1}$ and Richard J Auchus
}

Division of Endocrinology, Department of Internal Medicine, Southwesterm Medical Center, University of Texas, 5323 Harry Hines Boulevard, Suite Y-5.318, Dallas, Texas 75390-8857, USA

${ }^{1}$ Reproductive Biology and Medicine Program, National Institute of Child Health and Human Development, National Institutes of Health, Bethesda, Maryland, USA

${ }^{2}$ Department of Endocrinology and Metabolism, Leiden University Medical Center, Leiden, The Netherlands

${ }^{3}$ Institute of Clinical Chemistry \& Laboratory Medicine and Department of Medicine, University Hospital, Dresden, Germany

${ }^{4}$ Department of Medicine, Faculty of Medicine, P.J. Šafárik University, Košice, Slovak Republic

${ }^{5}$ Medical Oncology Branch, National Cancer Institute, National Institutes of Health, Bethesda, Maryland, USA

(Correspondence should be addressed to R J Auchus; Email: richard.auchus@utsouthwestern.edu)

${ }^{*} \mathrm{H}$ K Ghayee and B Havekes contributed equally to this work

\begin{abstract}
Extra-adrenal pheochromocytomas, otherwise known as paragangliomas (PGLs), account for about $20 \%$ of catecholamine-producing tumors. Catecholamine excess and mutations in the genes encoding succinate dehydrogenase subunits $(\mathrm{SDHx})$ are frequently found in patients with PGLs. Only $2 \%$ of PGLs are found in the mediastinum, and little is known about genetic alterations in patients with mediastinal PGLs, catecholamine production by these tumors, or their clinical behavior. We hypothesized that most mediastinal PGLs are associated with germ line SDHx mutations, norepinephrine and/or dopamine excess, and aggressive behavior. The objective of this study was to characterize genetic, biochemical, and clinical data in a series of ten patients with mediastinal PGLs. All ten primary mediastinal PGL patients had germ line SDHx mutations, six in SDHB, and four in SDHD genes. Chest or back pain were the most common presenting symptoms (five patients), and catecholamines and/or their metabolites were elevated in seven patients. Additional tumors included head and neck PGLs in four patients, pheochromocytoma in one patient, and bladder PGL in another. Metastatic disease was documented in six patients $(60 \%)$, and a concurrent abdominal mass was found in one patient. We conclude that mediastinal PGLs are strongly associated with SDHB and SDHD gene mutations, noradrenergic phenotype, and aggressive behavior. The present data suggest that all patients with mediastinal PGLs should be screened for SDHx gene mutations, regardless of age.
\end{abstract}

Endocrine-Related Cancer (2009) 16 291-299

\section{Introduction}

About $20 \%$ of catecholamine-producing tumors are derived from extra-adrenal chromaffin tissues and are termed paragangliomas (PGLs; Lenders et al. 2005). PGLs arise from chromaffin cells associated with sympathetic tissues. PGLs are found mostly in the abdomen, less commonly in the pelvic sympathetic plexus of the urinary bladder, and rarely in the mediastinum (Pacak et al. 2006).

PGLs may occur sporadically or as part of a hereditary syndrome. Multiple endocrine neoplasia type 2, neurofibromatosis type 1, and von Hippel-Lindau syndrome 
are familial syndromes that predominantly predispose to adrenal pheochromocytomas. By contrast, mutations in the genes encoding succinate dehydrogenase (SDH) subunits $\mathrm{B}, \mathrm{C}$, and $\mathrm{D}$ cause extra-adrenal PGLs associated with familial PGL syndromes PGL4, PGL3, and PGL1 respectively (Baysal et al. 2000, Niemann \& Muller 2000, Astuti et al. 2001). Germ line SDHB mutations are mainly associated with abdominal PGLs having aggressive and malignant behavior (GimenezRoqueplo et al. 2003, Neumann et al. 2004, Benn et al. 2006, Timmers et al. 2007, 2008). By contrast, germ line SDHD mutation carriers are frequently diagnosed with benign and often non-functional head and neck PGLs and/or pheochromocytomas. SDHD-associated malignant disease is considered rare (Benn et al. 2006, Havekes et al. 2007, Timmers et al. 2007). PGLs caused by germ line SDHB mutations show hypersecretion of both norepinephrine and dopamine in $46 \%$ and norepinephrine alone in $41 \%$ of cases (Timmers et al. 2007), whereas hypersecretion of norepinephrine appears to be most prevalent in SDHD-associated disease (van Houtum et al. 2005; unpublished data Havekes).

Approximately, 100 cases of mediastinal PGLs have been reported in the literature to date (Lamy et al. 1994, Bouhouch et al. 2007, Leshnower et al. 2007, Paul et al. 2007, Ramos et al. 2007, Kim et al. 2008), and $30 \%$ are associated with elevated catecholamines or metanephrines (Dunn et al. 1986, Pacak et al. 2006). About 5-20\% of mediastinal PGLs are malignant, but this estimate derives from a small series with divergent data (Mader et al. 1997, Sandur et al. 1999, Kim et al. 2008). Based on the data for PGLs in other sites, we hypothesized that most mediastinal PGLs are associated with germ line SDHx mutations, norepinephrine and/or dopamine excess, and aggressive behavior. We prospectively and retrospectively identified ten patients with mediastinal PGLs, screened them for mutations in SDHB and SDHD genes, characterized their biochemical features, and determined the prevalence of malignant disease in this cohort. These data allow us to define the biology of mediastinal PGLs and to formulate recommendations for clinicians about the approach to these patients.

\section{Patients and methods}

Patients in this PGL series derive from Parkland Memorial Hospital, Dallas, Texas; the National Institutes of Health (NIH), Bethesda, Maryland; the Leiden University Medical Center, Leiden, The Netherlands; and the Department of Medicine in Košice, Slovak Republic. All patients gave written and informed consent for genetic testing as approved by the institutional review board of each respective institution. Records of all patients enrolled in the NIH pheochromocytoma protocol were considered for inclusion. All of the patients with radiological and/or histopathological evidence of mediastinal PGLs, who could be studied by the investigators at these centers, were included in this survey.

Cases 1 and 2 were retrospectively and prospectively studied respectively, at Parkland Memorial Hospital. A total of six unrelated patients with a history of PGL were identified at the NIH and included in this retrospective study (patients 3-8). All of these patients were referred to the NIH for an outline of an optimal plan for (suspected) PGL. Patient 9 was retrospectively identified with a history of mediastinal PGL at the Leiden University Medical Center in Leiden, the Netherlands. Patient 10 was prospectively identified at the Department of Medicine in Košice, Slovak Republic. Patient characteristics are summarized in Table 1.

\section{Case reports}

\section{Case 1}

A 27-year-old African-American woman with a history of mediastinal PGL resected at the age of 21 presented with severe hypertension and palpitations. She developed recurrent non-radiating chest pain followed by gait abnormalities several months later. Computed tomography (CT) scan of the abdomen and lumbar spine revealed a $2.5 \mathrm{~cm}$ enhancing mass in the retroperitoneum, adjacent to the left psoas at the level of the aortic bifurcation. An $\left[{ }^{111} \mathrm{In}\right]$ pentetreotide scan showed a recurrence of the T4 vertebral body lesion but no uptake in the psoas mass. Chest $\mathrm{CT}$ showed a $2 \mathrm{~cm}$ heterogeneous mass at the T4 vertebral body with extension into the spinal canal as well as extensive bony destruction of T4. Plasma normetanephrine levels were elevated and metanephrine levels were normal. After adequate $\alpha$ - and $\beta$-adrenergic blockade, the patient underwent a preoperative embolization of the tumor, followed by a lateral extracavitary resection of her recurrent mediastinal and spinal PGLs. Resection of the psoas lesion demonstrated another PGL. Six and twelve months post-surgery, her plasma normetanephrine level was normal, and she was no longer hypertensive. Genetic testing revealed an SDHB mutation (c.725G $>$ A, p.Arg242His) and radiation therapy was started. Her mother was found to be an asymptomatic carrier of this mutation. One year after the diagnosis of recurrent PGL, her plasma normetanephrine level is still normal. 
Table 1 Patient characteristics

\begin{tabular}{|c|c|c|c|c|c|c|c|c|c|}
\hline & $\begin{array}{l}\text { Gender, } \\
\text { age }^{a} \text { (years) }\end{array}$ & $\begin{array}{l}\text { F/U } \\
\text { (years) }\end{array}$ & Mutation & $\begin{array}{l}\text { Biochemistry } \\
\text { (fold normal) }\end{array}$ & $\begin{array}{l}\text { Presenting } \\
\text { symptoms }\end{array}$ & $\begin{array}{l}\text { Primary mediastinal } \\
\text { tumor }\end{array}$ & $\begin{array}{l}\text { Other } \\
\text { PGL/Pheo }\end{array}$ & Therapy & Outcome \\
\hline 1 & $F, 18$ & 7 & $\begin{array}{l}\text { SDHB, } \\
\text { R242H }\end{array}$ & NM $(4 \times)$ & $\begin{array}{l}\text { Hypertension, palpi- } \\
\text { tations, chest pain }\end{array}$ & $\begin{array}{l}\text { T4 vertebral body } \\
(2.5 \mathrm{~cm}), \text { recurrent } \\
\text { disease }\end{array}$ & No & Thoracotomy, XRT & $\begin{array}{l}\text { Five years to meta } \\
\text { spine, psoas }\end{array}$ \\
\hline 2 & $F, 60$ & 1 & $\begin{array}{l}\text { SDHB, } \\
\text { G96D }\end{array}$ & NM $(11 \times)$ & $\begin{array}{l}\text { Chest pain, upper } \\
\text { back pain, weight } \\
\text { loss, hypertension }\end{array}$ & $\begin{array}{l}\text { T5-T7 vertebral body } \\
(7.5 \mathrm{~cm}), \text { epidural } \\
\text { space, thoracic wall, } \\
\text { paraspinal musculature }\end{array}$ & No & Surgical removal & Stable disease \\
\hline 3 & M, 25 & 7 & $\begin{array}{l}\text { SDHB, } \\
\text { R46X }\end{array}$ & Normal & Chest pain & $\begin{array}{l}\text { Posterior mediastinal } \\
\text { mass, left paraspinal } \\
\text { T2-T3 }(3.5 \mathrm{~cm})\end{array}$ & No & $\begin{array}{l}\text { Surgery paraspinal mass, } \\
\text { XRT lobectomy, thor- } \\
\text { acic corpectomy, } \\
\text { decompression, } \\
\text { fixation T1-T5 }\end{array}$ & $\begin{array}{l}\text { Four years to meta } \\
\text { lung, superior med- } \\
\text { iastinum, spine, } \\
\text { sternum, scapula } \\
6 \text { years to meta left } \\
\text { ischium, T3 and T4 }\end{array}$ \\
\hline 4 & M, 45 & 9 & $\begin{array}{l}\text { SDHD } \\
\quad \text { C. } 170-1 \\
\mathrm{G}>\mathrm{T}\end{array}$ & NM $(2.6 \times)$ & $\begin{array}{l}\text { Weakness, palpita- } \\
\text { tions, headaches, } \\
\text { hypertension }\end{array}$ & $\begin{array}{l}\text { Middle mediastinal mass } \\
(6 \mathrm{~cm}) \text { with com- } \\
\text { pression right main } \\
\text { pulmonary artery }\end{array}$ & HNP & $\begin{array}{l}\text { Embolization, partial } \\
\text { resection }\end{array}$ & $\begin{array}{l}\text { One year to recurrent } \\
\text { disease, meta lung, } \\
\text { subcarinal lesion, } \\
\text { proximal tibia }\end{array}$ \\
\hline 5 & M, 26 & 4 & $\begin{array}{l}\text { SDHB, } \\
\text { R46Q }\end{array}$ & Normal & $\begin{array}{l}\text { Low back pain, } \\
\text { hypertension }\end{array}$ & $\begin{array}{l}\text { Left superior mediasti- } \\
\text { num }(15.6 \mathrm{~cm}) \text { right } \\
\text { superior paratracheal } \\
\text { region inferior right } \\
\text { paratracheal lymph } \\
\text { nodes }\end{array}$ & $\begin{array}{l}\text { PGL } \\
\text { abdomen }\end{array}$ & $\begin{array}{l}\text { Surgery abdominal mass } \\
\text { six cycles etoposide/- } \\
\text { cisplatin octreotide }\end{array}$ & $\begin{array}{l}\text { Necrotic mass L4, } \\
\text { extending in pelvis, } \\
1 \text { year to meta } \\
\text { lesions L3 and L4 } \\
\text { and lymph nodes }\end{array}$ \\
\hline 6 & M, 19 & 19 & $\begin{array}{l}\text { SDHD, } \\
\text { L20C } \\
\text { fsX66 }\end{array}$ & NM $(2 \times)$ & $\begin{array}{l}\text { Hemodynamic } \\
\text { instability during } \\
\text { HNP surgery }\end{array}$ & Paratracheal mass $(2 \mathrm{~cm})$ & HNP Pheo & $\begin{array}{l}\text { Carotid body removal } \\
\text { right, adrenalectomy } \\
\text { right, XRT (HNP), } 12 \\
\text { cycles CVD, }{ }_{131} \text { I- } \\
\text { MIBG-therapy }\end{array}$ & $\begin{array}{l}\text { Fifteen years to } \\
\text { recurrence to } \\
\text { mediastinum. Meta } \\
\text { left ilium }\end{array}$ \\
\hline 7 & $\mathrm{~F}, 36$ & 6 & $\begin{array}{l}\text { SDHB, } \\
\text { R46X }\end{array}$ & $\begin{array}{l}\mathrm{NM}(3.5 \times) \\
\mathrm{DA}(1.9 \times)\end{array}$ & $\begin{array}{l}\text { Chest discomfort, } \\
\text { hypertension, pal- } \\
\text { pitations, pre-syn- } \\
\text { cope associated } \\
\text { with urination }\end{array}$ & $\begin{array}{l}\text { Posterior mediastinal } \\
\text { mass next to esopha- } \\
\text { gus, posterior wall left } \\
\text { atrium }(2.9 \mathrm{~cm})\end{array}$ & $\begin{array}{l}\text { PGL } \\
\text { bladder }\end{array}$ & $\begin{array}{l}\text { Partial cystectomy, } \\
\text { re-operation (negative), } \\
\text { surgery mediastinal } \\
\text { PGL }\end{array}$ & Stable disease \\
\hline 8 & $\mathrm{~F}, 50$ & 6 & $\begin{array}{l}\text { SDHD, } \\
\text { P81L }\end{array}$ & Normal & $\begin{array}{l}\text { Upper respiratory } \\
\text { symptoms, new- } \\
\text { onset hypertension }\end{array}$ & $\begin{array}{l}\text { Aorto-pulmonary window, } \\
\text { left and right hilus } \\
(3.3 \mathrm{~cm}) \text {, pulmonary } \\
\text { nodules }\end{array}$ & HNP & Pending & $\begin{array}{l}\text { Meta lung, mediasti- } \\
\text { num, } 6 \text { years later } \\
\text { being evaluated for } \\
\text { new-onset hyper- } \\
\text { tension }\end{array}$ \\
\hline 9 & $M, 41$ & 1 & $\begin{array}{l}\text { SDHD, } \\
\text { D92Y }\end{array}$ & $\begin{array}{l}\operatorname{VMA}(1.3 \times)^{b} \\
\operatorname{DA}(1.1 \times)^{b}\end{array}$ & $\begin{array}{l}\text { Excessive perspira- } \\
\text { tion }\end{array}$ & $\begin{array}{l}\text { Two masses in aorto- } \\
\text { pulmonary window } \\
(1 \mathrm{~cm})\end{array}$ & HNP & Watch-and-wait & Stable disease \\
\hline 10 & M, 18 & 1 & $\begin{array}{l}\text { SDHB, } \\
\text { c. } 286+2 \\
\quad T>A\end{array}$ & NM $(10 \times)$ & Hypertension & $\begin{array}{l}\text { Mass in posterior med- } \\
\text { iastinum }(9 \mathrm{~cm}) \text {, growth } \\
\text { into T5 }\end{array}$ & No & Surgery (incomplete) & Stable disease \\
\hline $\begin{array}{l}\text { Mean } \\
\text { (range) }\end{array}$ & $34(18-60)$ & & & & & $\begin{array}{l}\text { Primary tumor: } 5.3 \mathrm{~cm} \\
\quad(1-15.6)\end{array}$ & & & \\
\hline
\end{tabular}

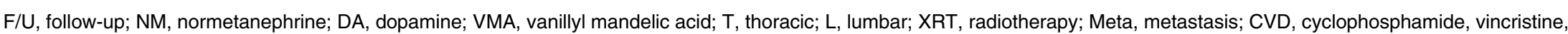
dacarbazine; HNP, head and neck paraganglioma; PGL, paraganglioma; Pheo, pheochromocytoma.

${ }^{a}$ Age at diagnosis.

bUrine measurement. 


\section{Case 2}

A 60-year-old Asian-Indian woman with a history of well-controlled hypertension and type 2 diabetes presented with complaints of worsening upper back pain, vague complaints of chest wall pain, and unintentional $25 \mathrm{~kg}$ weight loss over the preceding 6 months. A chest radiograph and later magnetic resonance imaging (MRI) revealed a $7.3 \mathrm{~cm}$ mass likely
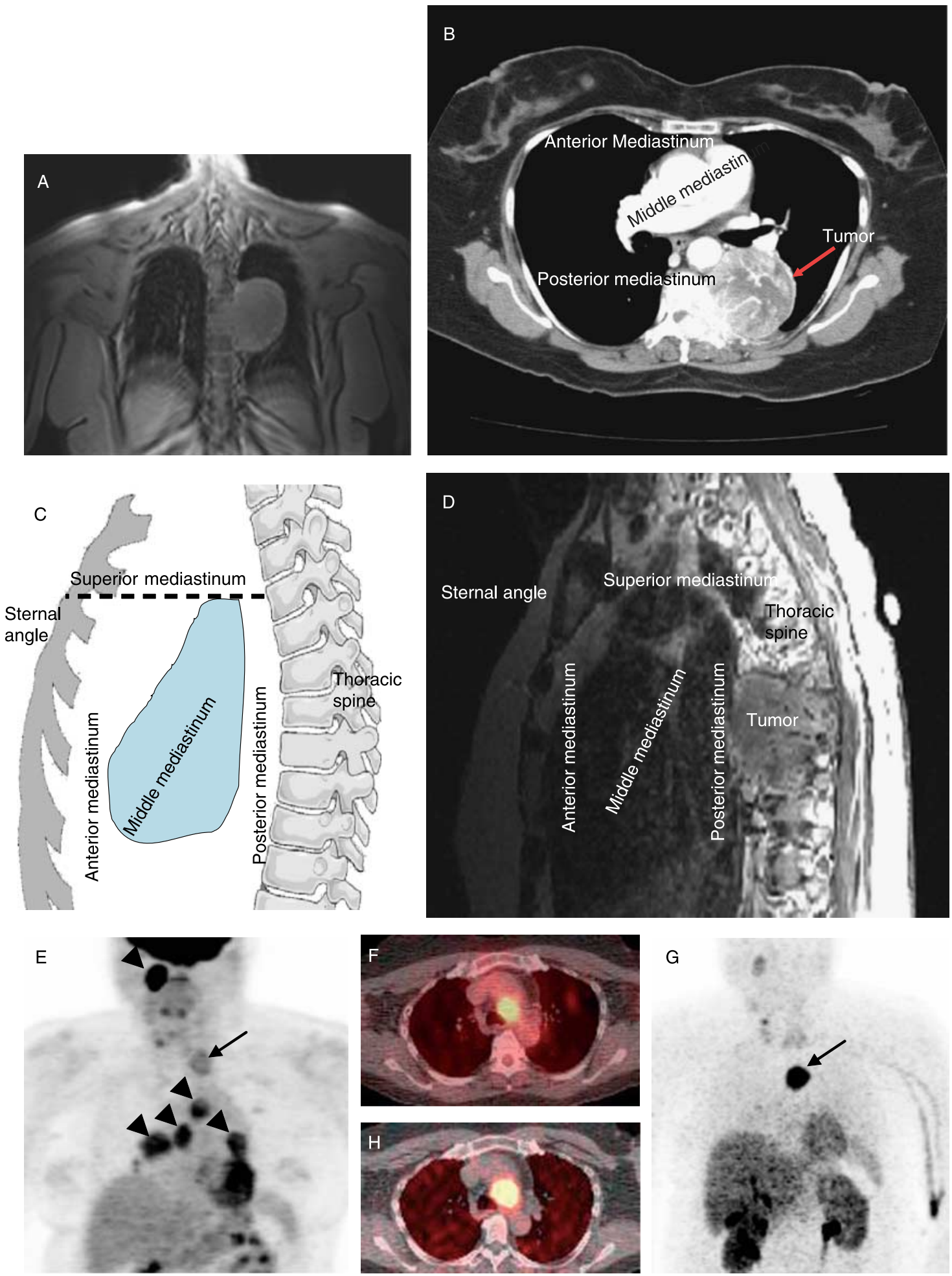

G
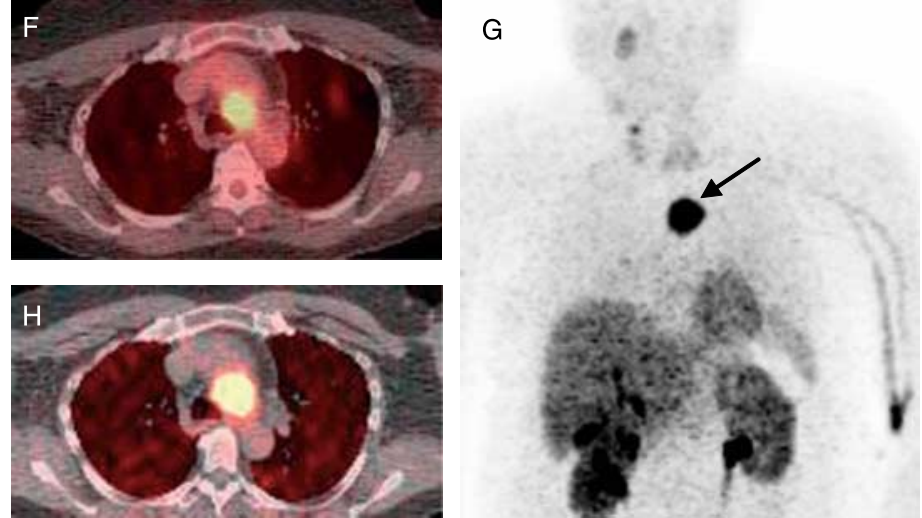
arising from the posterior mediastinum (Fig. 1A). Subsequently, chest CT (Fig. 1B) and MRI of the T-spine (Fig. 1C and D) showed a large left posterior mediastinal mass measuring $5.4 \times 5.2 \mathrm{~cm}$ with heterogeneous enhancement and central cystic/necrotic changes. The mass involved the left aspect of T5 and the majority of the T6 vertebral bodies, but PGL was not suspected. Fine needle biopsy of the mass was consistent with PGL, and plasma normetanephrine was elevated. After $\alpha$-adrenergic blockade, she was treated with two percutaneous embolizations followed by a two-stage resection of the mass using a T6 laminectomy and spine fusion from T3 to T9. Family history was negative for PGLs and pheochromocytomas. Genetic testing revealed an SDHB mutation (c. $287 \mathrm{G}>\mathrm{A}$, p.Gly96Asp) at the junction of exons 3 and 4 .

\section{Case 3}

A 25-year-old man was evaluated for a sharp pain on the left side of the chest. A posterior mediastinal mass was found on a chest X-ray. CT and MRI scans revealed a left paraspinal (T2-T3) mass. The left paraspinal mass was removed together with a partial resection of the T2 and T3 vertebrae. Histopathology revealed PGL cells with microvascular invasion. After surgery, he was treated with local radiotherapy and followed with periodic CT scans. Four years later, a $1.0 \times 1.2 \mathrm{~cm}$ nodule in the right middle lobe was detected, which had increased in size from previous CT scans. $\left[{ }^{18} \mathrm{~F}\right]$ Fluoro-deoxyglucose positron emission tomography ( $\left[{ }^{18} \mathrm{~F}\right] \mathrm{FDG}$ PET) tumor imaging showed uptake in the left sternum, scapula, right lower lung zone, left lung apex, posterior mediastinum, superior mediastinum, and thoracic spine. A lobectomy with lymph node extirpation was performed, and histopathology revealed PGL cells. A year after lobectomy and 6 years after his initial presentation, new pulmonary, thoracic spine, and paraspinal masses of $\sim 2.2 \mathrm{~cm}$ were detected in the area of $\mathrm{T} 3$ and $\mathrm{T} 4$ vertebrae. He underwent a partial thoracic corpectomy, as well as a posterior thoracic decompression and fixation of T1-T5 with an iliac crest bone graft.
Histopathology revealed a PGL with areas of necrosis. Family history was negative for both PGLs and pheochromocytomas. Plasma metanephrine levels, first measured 5 years after diagnosis, have been normal. Genetic analysis revealed an SDHB mutation (c.136C > T, p.Arg46Stop).

\section{Case 4}

A 45-year-old male patient was diagnosed with bilateral carotid body tumors, which he first noted while shaving as a mass in his right neck. Without further preoperative investigations or treatment, he underwent surgery with no hemodynamic problems. After the operation, however, he developed an irregular heart rhythm and resistant hypertension. Complaints of weakness, palpitations, and panic attacks led to a cardiac stress test that revealed dysrhythmias. A mediastinal tumor was found on chest X-ray, but PGL was not suspected. The mass was further localized by CT, and a biopsy revealed PGL cells. An embolization and partial tumor resection were performed due to localization adjacent to major vessels, esophagus, and trachea. A year later, repeat chest CT scan revealed a mediastinal mass of $\sim 6 \times 5 \mathrm{~cm}$ with compression of the right main pulmonary artery. He was referred to the NIH for further evaluation and therapy. His plasma normetanephrine levels were elevated. Imaging revealed multifocal PGL disease with recurrence of the carotid body tumor, a large mediastinal mass adjacent to the left atrium, metastatic lung lesions, and a mass in the left suprarenal area. Family history was positive for head and neck PGLs. Genetic analysis for germ line mutations revealed an SDHD mutation (c.170-1G $>\mathrm{T}$, splice site mutation).

\section{Case 5}

A 26-year-old man complained of progressive lower back pain after exercise. A CT scan showed a large enhancing necrotic retroperitoneal mass measuring $13.4 \times 8.5 \times 15.6 \mathrm{~cm}$, metastatic lesions in L3 and L4, a $3.1 \times 2.5 \mathrm{~cm}$ in diameter lesion in the superior right

Figure 1 Imaging studies. (A) Chest MRI of patient 2 (coronal T1-weighted FOV three-plain localizing image; TR, 66.5 ms; TE, $1.5 \mathrm{~ms}$ ) showing mediastinal mass. (B) Chest CT of patient 2 following i.v. contrast showing same paraganglioma. (C) Illustration of mediastinal compartments. The anterior mediastinum is defined as the space bordered by the sternum anteriorly and the ventral cardiac surface posteriorly, including the thymus and ascending aorta. The middle mediastinum is posterior to the anterior mediastinum and is bordered posteriorly by the anterior surface of the spine; the middle compartment includes the heart, esophagus, trachea, and major blood vessels. The posterior mediastinum is posterior to the anterior surface of the spine and contains the descending aorta, spine, and ribs. The superior mediastinum is defined by a horizontal line from the angle of Louis posteriorly to the spine as the inferior border and includes the thyroid, aortic arch, and superior parts of the esophagus and trachea. (D) MRI of patient 2 (sagittal T1-weighted images after gadolinium contrast; TR, $417 \mathrm{~ms}$; TE, $13 \mathrm{~ms}$ ) showing posterior mediastinal PGL. (E) Coronal $\left[{ }^{18} \mathrm{~F}\right]$ FDG PET scan of patient 8 , showing superior mediastinal PGL (arrow) plus additional lesions in the head, neck, and upper chest (arrowheads); axial CT-PET in (F) localizes mediastinal PGL near the aortic arch. (G) Coronal $\left[{ }^{18} \mathrm{~F}\right]$ fluorodopamine PET scan of patient 8 shows localization of mediastinal PGL concordant with $\left[{ }^{18} \mathrm{~F}\right] \mathrm{FDG}$ PET (arrow), which was confirmed on axial CT-PET in (H). 
paratracheal region, a $3.4 \times 2.5 \mathrm{~cm}$ in diameter lesion within the left superior mediastinum, and multiple enlarged lymph nodes. All of his plasma metanephrine levels were normal. A biopsy revealed no conclusive diagnosis. His plasma catecholamine levels and their $O$-methylated compounds were all normal. He underwent an uncomplicated surgical removal of the abdominal mass, which proved to be PGL on histopathology. He was treated with six cycles of etoposide and cisplatin chemotherapy with limited effect, followed briefly by octreotide. Follow-up revealed persistent masses in the left and right superior mediastinal area, lower abdomen, retroperitoneal region, L3-L4 vertebrae, and the right humerus. Plasma catecholamine levels remained normal, but chromogranin A was elevated. Follow-up studies 1 year later revealed stable disease. Family history was negative for PGLs and pheochromocytomas. Genetic analysis revealed an SDHB mutation (c.137G $>$ A, p.Arg46Gln).

\section{Case 6}

A 19-year-old male initially presented in with hematemesis. He was found to have a gastric leiomyosarcoma (gastrointestinal stromal cell tumor or GIST), which was resected. Two years later, a right carotid body tumor was diagnosed and removed. He subsequently developed elevated catecholamines and hypertension due to a pheochromocytoma in the right adrenal gland, which was surgically removed as well. On additional imaging studies, a paratracheal mass and a left glomus jugulare tumor were identified, and the latter was treated with radiation therapy (4000 cGy). Thirteen years after his initial episode of hematemesis, he presented himself to the NIH for further evaluation of PGL. A chest and abdominal CT scan showed a mass in the left superior mediastinum and abdominal metastases including lesions in the liver, with similar $\left[{ }^{123} \mathrm{I}\right] \mathrm{MIBG}$ uptake. Urinary biochemistry revealed increased levels of norepinephrine, vanillyl mandelic acid (VMA), and normetanephrine. He was treated with 12 cycles of cyclophosphamide, vincristine, and dacarbazine under continuing $\alpha$-adrenergic blockade with prazosin. $\left[{ }^{18} \mathrm{~F}\right] \mathrm{FDG}$ PET showed uptake in the paratracheal mass with intense activity, a focus in $\mathrm{T} 8$ vertebra, two abdominal masses, and six liver lesions. The patient was treated with $\left[{ }^{131} \mathrm{I}\right] \mathrm{MIBG}$. Presently, there is stable metastatic disease with a suspect $2 \mathrm{~cm}$ lesion in the left ilium. Plasma normetanephrine levels remain elevated. Family history was negative for PGLs and pheochromocytomas. Genetic analysis revealed an SDHD mutation (c.57delG, p.Leu20Cys-fs-Stop66), and some children have subsequently tested positive for this mutation.

\section{Case 7}

A 36-year-old female patient complained of episodic hypertension, palpitations, chest discomfort, presyncope and shortness of breath, particularly associated with urination, for a few years. Biochemical and imaging studies revealed a $0.4 \times 4.0 \mathrm{~cm}$ pheochromocytoma located in the anterior urinary bladder, which was removed. After surgery, catecholamine levels remained elevated, and chest MRI revealed a mediastinal mass with a diameter of $2.3 \mathrm{~cm}$ next to the esophagus. Although $\left[{ }^{123} \mathrm{I}\right] \mathrm{MIBG}$ scintigraphy revealed no definite abnormalities, $\left[{ }^{18}\right.$ F]FDG PET and $\left[{ }^{111} \mathrm{In}\right]$ pentetreotide both showed uptake in the same area of the posterior mediastinum. An echocardiogram localized this $2.9 \times 2.2 \times 2.4 \mathrm{~cm}$ mass to the posterior wall of the left atrium adjacent to the right lower pulmonary vein. Plasma normetanephrine and dopamine levels were elevated. The intracardiac PGL was surgically removed. Follow-up imaging has not shown persistent or recurrent disease, and catecholamines remain normal. Family history was negative for PGLs, but genetic testing revealed an SDHB mutation (c.136C > T, p.Arg46Stop).

\section{Case 8}

A 50-year-old woman was referred to the NIH with suspected metastatic PGL. Right and left carotid body tumors had been removed at the ages of 19 and 30 respectively. She did well until she experienced one episode of palpitations, anxiety, and headache, 1 year prior to presentation. Chest X-ray for upper respiratory symptoms showed a mass in the mediastinum. CT and MRI revealed lesions in the left neck, the AP window $(2.8 \mathrm{~cm})$, the left hilus $(3.3 \mathrm{~cm})$, and the right hilus $(3 \mathrm{~cm})$, plus multiple parenchymal lung nodules. Her plasma catecholamine and metanephrine levels were within normal limits. The mediastinal and neck lesions were found to be positive on $\left[{ }^{18} \mathrm{~F}\right]$ fluorodopamine PET and $\left[{ }^{111} \mathrm{In}\right]$ pentetreotide imaging. Because of stable asymptomatic disease, a watch-and-wait management was chosen, but hypertension and palpitations developed 6 years later. Progressive multilevel metastatic disease was found on $\left[{ }^{18}\right.$ F]FDG PET and $\left[{ }^{18} \mathrm{~F}\right]$ fluorodopamine imaging (Fig. 1E-H) with the known mediastinal lesion, four additional lesions in the mediastinum, four lung lesions, and a suspected lesion in the sacrum. Family history was positive for carotid body tumor in a brother. Genetic analysis revealed an SDHD mutation (c.242C > T, p.Pro81Leu). 


\section{Case 9}

A 41-year-old man was diagnosed with bilateral head and neck PGLs after an analysis for hearing loss and tinnitus. Besides excess sweating, no paroxysms or other complaints were mentioned. Physical examination revealed no further abnormalities. Twenty-fourhour urine collection revealed elevated VMA, without elevation of other catecholamines; metanephrines were not measured. [ $\left.{ }^{123} \mathrm{I}\right] \mathrm{MIBG}$ scintigraphy showed no pathological uptake. Abdominal MRI identified a $1 \mathrm{~cm}$ nodule in the left adrenal consistent with an adenoma. Chest CT revealed two $\sim 1 \mathrm{~cm}$ hypervascular lesions in the aorto-pulmonary window, suspicious of PGL. $\left[{ }^{111} \mathrm{In}\right]$ pentetreotide scan and $\left[{ }^{18} \mathrm{~F}\right]$ fluorodopamine PET scan revealed increased uptake in these lesions. Family history was negative for pheochromocytoma or PGL. Subsequent genetic analysis revealed an SDHD gene mutation (c.274G $>$ T, p.Asp92Tyr). Given the lack of symptoms, the reported low risk for malignant disease with SDHD mutations, and considerable risks of surgery, a watch-and-wait strategy was chosen.

\section{Case 10}

An 18-year-old man was admitted to the hospital with a blood pressure of $220 / 120 \mathrm{mmHg}$. Plasma normetanephrine levels were found to be ten times elevated, and pheochromocytoma was strongly suspected. On CT and $\left[{ }^{123}\right.$ I]MIBG imaging, a $9 \times 7 \times 5 \mathrm{~cm}$ tumor was found in the posterior mediastinum with growth into $\mathrm{T} 5$ vertebra. An operation was performed with incomplete tumor removal, and histopathology showed PGL. Family history revealed that his father died suddenly and had head and neck PGLs. Genetic analysis revealed an SDHB mutation (c.286+2T $>$ A, splice site mutation).

\section{Discussion}

Only $2 \%$ of PGLs are found in the mediastinum (Pacak et al. 2006), and their associated genetic alterations, biochemical features, and clinical behavior have not been systematically characterized. The major new finding in this report is that all ten patients with mediastinal PGLs were associated with germ line mutations in either SDHB or SDHD. Of these ten patients, at least $60 \%$ developed metastatic disease, indicating that these tumors are often aggressive and should be carefully followed. Furthermore, we found that chest or back pain and norepinephrine excess are common in patients with mediastinal PGLs, and high metabolic activity was demonstrated by $\left[{ }^{18} \mathrm{~F}\right] \mathrm{FDG}$ PET in cases 3,6 , and 7 . We conclude that all patients with mediastinal PGLs should be screened for germ line SDHx mutations, regardless of age.

Carriers of the germ line SDHD mutations often present with multifocal head and neck PGLs (Benn et al. 2006). Germ line SDHB mutations predispose patients to extra-adrenal PGLs, often in the abdomen, and to metastatic disease in 30-50\% (Neumann et al. 2004, Timmers et al. 2007). We reasoned that mediastinal PGLs might provide insight to how germ line SDHx mutation and anatomic location each contribute to their clinical behavior. We found that the SDHB-associated mediastinal PGLs involved metastatic disease (cases 1, 3 , and 5) as expected, but we also found two cases of SDHB associated PGLs to have multifocal disease (cases 5,7). By contrast, all of the SDHD-associated mediastinal PGLs involved multifocal tumors as expected, yet $75 \%$ of the patients also suffered from metastatic disease as well (cases 4, 6, and 8). Consequently, the presence of a mediastinal PGL may identify patients with aggressive PGL syndromes, both with germ line SDHB and SDHD mutations (Table 2). In comparison, intra-abdominal PGLs are malignant in about a third of cases, particularly with SDHB mutations, and multifocal disease is present in 15$40 \%$ of cases (O'Riordain et al. 1996, Pacak et al. 2006). During the submission of this manuscript, a series of 14 mediastinal PGLs was reported, also showing a high prevalence of metastatic or recurrent disease (Brown et al. 2008). This study included two cases of Carney triad and three with a family history of PGL; however, germ line SDHx mutations were only characterized in two of these three cases and not in the remaining ten patients.

Half of our patients presented with an age $<30$ years old, which is typical of PGL syndromes, but others were 50-60 years old. A convincing family history of PGL was present in only $30 \%$, reinforcing the variable

Table 2 Comparison of paragangliomas (PGL) characteristics by location and succinate dehydrogenase subunits (SDHx) mutations

\begin{tabular}{lllll}
\hline Gene & & & & SDHB \\
\hline Location & SDHD & & Mediastinum & Abdomen \\
Catecholamines & None $>$ NE & Mediastinum & NE, DA & NE, DA \\
Multifocal & Common & NE, DA & Common & Rare \\
Malignant & Rare & Common & Common & Common \\
\hline
\end{tabular}

NE, norepinephrine; DA, dopamine. 
penetrance of germ line SDHx mutations. Experienced genetic counseling is therefore recommended in patients with mediastinal PGLs, and strong consideration should be given to genetic screening of first-degree relatives.

PGLs associated with germ line SDHB mutations often produce norepinephrine and/or dopamine (Timmers et al. 2007). Although SDHD-associated PGLs are often non-functional if located in the head and neck, it may present with a noradrenergic biochemical phenotype (van Houtum et al. 2005). In seven out of the ten patients with mediastinal PGLs (four with SDHB and three with SDHD germ line mutations), excess norepinephrine and/or its metabolite normetanephrine was present, of which patient 9 had only borderline elevations. In two patients, excess dopamine was also found at presentation or follow-up. Our findings are consistent with other reports of SDHB-associated PGLs predominantly secreting norepinephrine (Timmers et al. 2007), yet three out of four SDHD-associated mediastinal PGLs also showed norepinephrine excess. Although dopamine has been reported to be associated with malignant disease (Eisenhofer et al. 2005), the two patients (cases 7 and 9) in our series with dopamineproducing PGLs presented with non-metastatic disease. We conclude that mediastinal PGLs tend to display a noradrenergic or dopaminergic biochemical phenotype, regardless of germ line SDHx mutation. Nevertheless, normal catecholamine production does not exclude mediastinal PGL.

Mediastinal PGLs typically occur in either the aortopulmonary window (in the region of the aortic arch) or in the posterior mediastinum (Drucker et al. 1987). The majority of patients in our series had tumor involvement in the posterior mediastinum (Fig. 1C and D). Nonspecific chest or back pain mimicking musculoskeletal pain was the most common presenting symptoms, found in six out of ten patients (Table 1), which may have contributed to delay in diagnosis as in patient 1. Pain as a presenting symptom has been reported in SDHB-related malignant PGLs (Timmers et al. 2007), and frequent malignant disease in our cohort probably contributed to the high prevalence of pain. At least half of our patients reported complaints related to catecholamine excess as well (Table 1).

Definitive therapy for PGLs remains surgical removal, with mediastinal location a complicating factor. Since most mediastinal PGLs secrete catecholamines, we strongly recommend that all of these patients are treated with appropriate $\alpha$-adrenergic blockade prior to surgical removal of the tumor (Pacak 2007). We also urge a high index of suspicion for the diagnosis of PGL when evaluating a paraspinal mass in the mediastinum, with biochemical screening and $\alpha$-adrenergic blockade prior to attempting biopsies as well. No randomized trials have evaluated the efficacy of post-operative radiation, $\left[{ }^{131}\right.$ I] MIBG treatment, or chemotherapy for thoracic PGLs. Consequently, it is presently unknown whether post-operative treatments improve outcomes for unresectable tumors and metastatic disease, or whether adjuvant therapies prevent recurrence (Thines et al. 2006, Scholz et al. 2007). When therapy-associated morbidity and cost outweigh treatment benefits, the aggressive disease associated with mediastinal PGLs mandates careful surveillance, both for SDHB and SDHD-associated disease.

In conclusion, mediastinal PGLs are frequently associated with germ line SDHx mutations, norepinephrine or dopamine production, aggressive disease, and multifocal tumors. High metabolic activity is demonstrated in some cases (Fig. 1). Prior to any invasive procedures, biochemical screening and adequate $\alpha$-adrenergic blockade is strongly recommended. All mediastinal PGLs should be screened for germ line SDHx mutations, regardless of age. Given the number of cases studied and limited follow-up in this series, more data are needed to determine the full spectrum of disease in patients with mediastinal PGLs and the best post-operative treatments for those with residual disease.

\section{Declaration of interest}

The authors declare no conflict of interest prejudicing the impartiality of the research.

\section{Funding}

This research was supported (in part) by the Intramural Research Program of the NIH/NICHD as well as the Clinical Scientist Award in Translational Research (\#1005954) from the Burroughs Wellcome Fund (to R J Auchus).

\section{Acknowledgements}

We thank Thanh Truc Huynh for assistance with SDHx genotyping. We thank Dr Naim Maalouf from the Division of Endocrinology and Dr Kevin Morrill from the Department of Neurosurgery at the University of Texas Southwestern Medical Center for helpful discussions.

\section{References}

Astuti D, Latif F, Dallol A, Dahia PL, Douglas F, George E, Skoldberg F, Husebye ES, Eng C \& Maher ER 2001 Gene mutations in the succinate dehydrogenase subunit SDHB cause susceptibility to familial pheochromocytoma and to familial paraganglioma. American Journal of Human Genetics 69 49-54. 
Baysal BE, Ferrell RE, Willett-Brozick JE, Lawrence EC, Myssiorek D, Bosch A, van der Mey A, Taschner PE, Rubinstein WS, Myers EN et al. 2000 Mutations in SDHD, a mitochondrial complex II gene, in hereditary paraganglioma. Science $\mathbf{2 8 7} 848-851$.

Benn DE, Gimenez-Roqueplo AP, Reilly JR, Bertherat J, Burgess J, Byth K, Croxson M, Dahia PL, Elston M, Gimm O et al. 2006 Clinical presentation and penetrance of pheochromocytoma/paraganglioma syndromes. Journal of Clinical Endocrinology and Metabolism 91 827-836.

Bouhouch A, Hendriks JM, Lauwers PR, De Raeve HR \& Van Schil PE 2007 Asymptomatic pheochromocytoma in the posterior mediastinum. Acta Chirurgica Belgica 107 465-467.

Brown ML, Zayas GE, Abel MD, Young WF Jr \& Schaff HV 2008 Mediastinal paragangliomas: the Mayo Clinic experience. Annals of Thoracic Surgery 86 946-951.

Drucker EA, McLoud TC, Dedrick CG, Hilgenberg AD, Geller SC \& Shepard JA 1987 Mediastinal paraganglioma: radiologic evaluation of an unusual vascular tumor. American Journal of Roentgenology 148 521-522.

Dunn GD, Brown MJ, Sapsford RN, Mansfield AO, Hemingway AP, Sever PS \& Allison DJ 1986 Functioning middle mediastinal paraganglioma (phaeochromocytoma) associated with intercarotid paragangliomas. Lancet 1 1061-1064.

Eisenhofer G, Goldstein DS, Sullivan P, Csako G, Brouwers FM, Lai EW, Adams KT \& Pacak K 2005 Biochemical and clinical manifestations of dopamine-producing paragangliomas: utility of plasma methoxytyramine. Journal of Clinical Endocrinology and Metabolism 90 2068-2075.

Gimenez-Roqueplo AP, Favier J, Rustin P, Rieubland C, Crespin M, Nau V, Khau Van Kien P, Corvol P, Plouin PF \& Jeunemaitre X 2003 Mutations in the SDHB gene are associated with extra-adrenal and/or malignant phaeochromocytomas. Cancer Research 63 5615-5621.

Havekes B, Corssmit EP, Jansen JC, van der Mey AG, Vriends AH \& Romijn JA 2007 Malignant paragangliomas associated with mutations in the succinate dehydrogenase D gene. Journal of Clinical Endocrinology and Metabolism 92 1245-1248.

van Houtum WH, Corssmit EP, Douwes Dekker PB, Jansen JC, van der Mey AG, Brocker-Vriends AH, Taschner PE, Losekoot M, Frolich M, Stokkel MP et al. 2005 Increased prevalence of catecholamine excess and phaeochromocytomas in a well-defined Dutch population with SDHD-linked head and neck paragangliomas. European Journal of Endocrinology 152 87-94.

Kim KN, Lee KN, Roh MS, Choi PJ \& Yang DK 2008 Pulmonary paraganglioma manifesting as an endobronchial mass. Korean Journal of Radiology 9 87-90.

Lamy AL, Fradet GJ, Luoma A \& Nelems B 1994 Anterior and middle mediastinum paraganglioma: complete resection is the treatment of choice. Annals of Thoracic Surgery 57 249-252.

Lenders JW, Eisenhofer G, Mannelli M \& Pacak K 2005 Phaeochromocytoma. Lancet 366 665-675.
Leshnower BG, Morris RJ \& Pechet TT 2007 Management of an anterior mediastinal pheochromocytoma causing tracheomalacia. Annals of Thoracic Surgery 84 20882090.

Mader MT, Poulton TB \& White RD 1997 Malignant tumors of the heart and great vessels: MR imaging appearance. Radiographics 17 145-153.

Neumann HP, Pawlu C, Peczkowska M, Bausch B, McWhinney SR, Muresan M, Buchta M, Franke G, Klisch J, Bley TA et al. 2004 Distinct clinical features of paraganglioma syndromes associated with SDHB and SDHD gene mutations. Journal of the American Medical Association 292 943-951.

Niemann S \& Muller U 2000 Mutations in SDHC cause autosomal dominant paraganglioma, type 3. Nature Genetics 26 268-270.

O'Riordain DS, Young WF Jr, Grant CS, Carney JA \& van Heerden JA 1996 Clinical spectrum and outcome of functional extraadrenal paraganglioma. World Journal of Surgery 20 916-922.

Pacak K 2007 Preoperative management of the pheochromocytoma patient. Journal of Clinical Endocrinology and Metabolism 92 4069-4079.

Pacak K, Keiser HR \& Eisenhofer G 2006 Pheochromocytoma. In Endocrinology, pp 2501-2534. Eds LJ deGroot \& JL Jameson., 5 Philadelphia: Elsevier.

Paul S, Jain SH, Gallegos RP, Aranki SF \& Bueno R 2007 Functional paraganglioma of the middle mediastinum. Annals of Thoracic Surgery 83 e14-e16.

Ramos R, Moya J, Villalonga R, Morera R \& Ferrer G 2007 Mediastinal aortosympathetic paraganglioma: report of two cases. Asian Cardiovascular \& Thoracic Annals 15 e49-e51.

Sandur S, Dasgupta A, Shapiro JL, Arroliga AC \& Mehta AC 1999 Thoracic involvement with pheochromocytoma: a review. Chest 115 511-521.

Scholz T, Eisenhofer G, Pacak K, Dralle H \& Lehnert H 2007 Clinical review: current treatment of malignant pheochromocytoma. Journal of Clinical Endocrinology and Metabolism 92 1217-1225.

Thines L, Lejeune JP, Ruchoux MM \& Assaker R 2006 Management of delayed intracranial and intraspinal metastases of intradural spinal paragangliomas. Acta Neurochirurgica 143 63-66 (discussion 66).

Timmers HJ, Kozupa A, Eisenhofer G, Raygada M, Adams KT, Solis D, Lenders JW \& Pacak K 2007 Clinical presentations, biochemical phenotypes, and genotypephenotype correlations in patients with succinate dehydrogenase subunit B-associated pheochromocytomas and paragangliomas. Journal of Clinical Endocrinology and Metabolism 92 779-786.

Timmers HJ, Pacak K, Bertherat J, Lenders JW, Duet M, Eisenhofer G, Stratakis CA, Niccoli-Sire P, Tran BH, Burnichon $\mathrm{N}$ et al. 2008 Mutations associated with succinate dehydrogenase D-related malignant paragangliomas. Clinical Endocrinology 68 561-566. 